\title{
A comparison of the effects of medial frontal, dorsomedial thalamic, and combination lesions on discrimination and spontaneous alternation in the rat
}

\author{
BONITA J. WEIS and LARRY W. MEANS \\ East Carolina University, Greenville, North Carolina 27834
}

\begin{abstract}
Two experiments were conducted to investigate the hypothesis that the medial frontal cortex and dorsomedial thalamus constitute a neural system mediating a common set of behaviors. Rats with bilateral medial frontal lesions, unilateral medial frontal lesions, bilateral medial thalamic lesions, unilateral medial thalamic lesions, contralateral medial frontal and medial thalamic lesions, and sham operations were compared on spontaneous alternation and visualtactile discrimination. Only rats with bilateral medial thalamic lesions were found to be deficient on the two tasks. Thus, while the present experiments are consistent with earlier work demonstrating that a functional medial thalamus is necessary for normal spontaneous alternation and discrimination, the present experiments failed to support the notion that the medial thalamus and medial frontal cortex constitute a common behavioral system.
\end{abstract}

Work from several laboratories has produced a relatively precise description of the anatomical connections between the dorsomedial nucleus of the thalamus (MD) and the prefrontal cortex in the rat (Divac, Kosmal, Bjorklund, \& Lindvall, 1976; Krettek \& Price, 1977; Leonard, 1969, 1972). The MD has been shown to consist of three distinct areas which project to seven distinct cortical areas covering much of the frontal pole. Essentially, the MD projects to the medial wall of the prefrontal cortex, anterior and dorsal to the genu of the corpus callosum, to the anterior angulate cortex, to the dorsal bank of the rhinal sulcus, and to the ventral surface of the frontal pole (orbital cortex). Also, projections to the reticular nucleus, head of the caudate nucleus, and amygdala have been shown (Domesick, 1972; Ebbesson, Jane, \& Schroeder, 1972; Krettek \& Price, 1977). Further reciprocal connections between the prefrontal cortex and the MD have been demonstrated in monkeys and cats (Akert, 1964; Nauta, 1971).

A series of experiments by Fuster and Alexander (Alexander \& Fuster, 1973; Fuster, 1973; Fuster \& Alexander, 1970, 1973) on monkeys strongly suggest a functional relationship between the MD and prefrontal cortex. They found that cooling the prefrontal cortex led to a delayed-response deficit and a change in the cell firing rate of the MD. Furthermore, changes in the firing rates of cells in the prefrontal cortex were found to be comparable to changes

This paper is based on a thesis submitted by Bonita J. Weis to East Carolina University in partial fulfillment of the MA degree and was supported in part by the East Carolina University Graduate Research Council. Reprint requests should be sent to Larry W. Means, East Carolina University, Greenville, North Carolina 27834. observed in MD. Thus, the delayed response task and neuronal firing changes provide strong evidence for a functional relationship between the MD and prefrontal cortex.

The purpose of the experiments herein reported is to determine if the dorsomedial thalamus (DMT) and the anteromedial cortex (AC), one of the major projection areas of the MD, constitute a single behavioral mediating system. It was reasoned that if these two structures constitute a single behaviormediating system, then bilateral disruption at either structure or unilateral disruption to one with contralateral damage to other should produce the same deficit pattern. Thus, rats with bilateral DMT, bilateral AC, and contralateral DMT-AC lesions were compared on two tasks on which we have previously shown rats with DMT lesions to be deficient (Means, Harrell, Mayo, \& Alexander, 1974; Means, Huntly, Anderson, \& Harrell, 1973).

\section{GENERAL METHOD}

\section{Subjects}

The study involved 38 naive, male Long-Evans rats from the East Carolina University Psychology Department colony. The rats were 90 to 120 days old at the time of surgery. The animals were housed in separate cages and maintained on a 14-h-light, 10-hdark cycle. The same rats were used for both of the experiments.

\section{Design}

Each subject was assigned randomly to one of six groups: a sham-operated group $(S)(n=7)$, a unilateral dorsomedial thalamic group (UD) $(n=5)$, a unilateral frontal group (UF) $(n=3)$, a bilateral dorsomedial thalamic group (BD) $(n=6)$, a bilateral frontal group $(\mathrm{BF})(\mathrm{n}=10)$, and a group with a contralateral lesion in the frontal cortex and the dorsomedial thalamus $(C)(n=7)$. All groups followed the same procedures for handling, surgery, recuperation, and postoperative testing. 


\section{Procedure}

Surgery. After 3 days, on each of which each animal was handled individually for $5 \mathrm{~min}$, surgery was performed, using Nembutal $(50 \mathrm{mg} / \mathrm{kg})$ as an anesthetic and $.2 \mathrm{cc}$ of Bicillin as an infection preventative. All of the animals receiving medial thalamic lesions were placed in the stereotaxic frame with the incisor bar positioned $5.0 \mathrm{~mm}$ above the ear bars. Group BD received $1.8 \mathrm{~mA}$ anodal current through stainless steel electrodes insulated with Krylon. The electrode was placed at the following coordinates: $\mathrm{A}-\mathrm{P}=-1.2, \mathrm{~L}= \pm 1.0, \mathrm{D}-\mathrm{V}=-6.2$, and the current was passed for $15 \mathrm{sec}$. The UD group had a similar lesion to only one side of the brain. Group BF had the anteromedial frontal cortex removed bilaterally by aspiration. Group UF had only one side of the anteromedial cortex aspirated. Group $\mathrm{C}$ received a dc lesion to one side of the dorsomedial thalamus and an anteromedial cortical aspiration lesion to the contralateral side. The procedure followed for Group S was almost identical to that of Group C, except that the electrode was lowered only $5.0 \mathrm{~mm}$ without current and the medial ccrtex was merely exposed on the opposite side.

Postsurgery. Following surgery, all animals were returned to their home cages and allowed to recuperate for at least 14 days. The animals were maintained on ad-lib food until the adaptation phase of the visual-tactile discrimination task. Once again, the rats were handled for $5 \mathrm{~min}$ daily for 3 days prior to testing.

Neuroanatomical analysis. Upon the completion of behavioral testing, all rats were sacrificed with an overdose of Nembutal. They were then perfused with a $.9 \%$ saline solution, followed by $10 \%$ Formalin, and the brains were extracted. Three different histological techniques were employed. Sixteen brains (1-UF and 15-BD) were frozen and sectioned at 50 microns. Every fourth section was photographed. Two of the BF group were imbedded in paraffin and sectioned at 10 microns, saving every sixth section. These sections were then stained with hematoxylin and eosin. The remaining 29 brains (12-C, 12-BF, 3-UF, and 2-BD) were imbedded in gelatin and sectioned, while frozen, at 50 microns. Every fifth section was stained with thionin.

\section{Anatomical Results}

A typical lesion for Group BD is reconstructed in Figure 1. All six rats in Group BD sustained bilateral damage to the MD, the parafascicular nucleus, the paraventricular nucleus, the stria medullaris, the anterodorsal nucleus, the lateral nucleus, the lateral habenular nucleus, the medial habenular nucleus, and the habenulointerpeduncular tract.

A reconstruction of a typical lesion for Group UD is given in Figure 1. All five animals in Group UD sustained unilateral damage to MD, parafascicular nucleus, stria medullaris, anterodorsal nucleus, habenular nucleus, medial habenular nucleus, and the habenulointerpeduncular tract.

Figure 2 shows reconstructions of two representative lesions for Group BF. In Group BF, the anteromedian frontal cortex was damaged bilaterally in all 10 subjects. The subcortical white matter and corpus callosum were invaded bilaterally in four animals, with one of these sustaining damage to the caudate nucleus. Three animals had lesions comparable to animal 17 (See Figure 2), in which the ventral portions of the anteromedian cortex was spared.

The three animals in Group UF had unilateral lesions of the anteromedial frontal cortex, with one sustaining damage to the anterior corpus callosum.

The seven animals in Group $C$ had unilateral damage to the anteromedian frontal cortex, five had lesions involving the corpus callosum, and two sustained slight unilateral damage to the caudate nucleus. The thalamic damage for this group was similar to that reported for Group UD.

\section{EXPERIMENT 2 SPONTANEOUS ALTERNATION}

Spontaneous alternation is a phenomenon in which an animal on the second exposure to an unbaited Tmaze will choose to enter the arm opposite to the one visited on the first trial. Normal rats are reported to perform this alternation $80 \%$ to $90 \%$ of the time (Dember \& Fowler, 1958; Means, Leander, \& Isaacson, 1971). Damage to the DMT causes rats to spontaneously alternate at chance level (Means et al., 1974). Furthermore, lesions of the anteromedial frontal cortex in the rat interfere with the performance of spontaneous alternation (Divac, Wikmark, \& Gade, 1975).

Since both DMT and AC lesions have been shown to produce deficits on spontaneous alternation and since contralateral DMT-AC lesions constitute bilateral disruption of a DMT-AC system, it was hypothesized that Groups BD, BF, and $C$ would spontaneously alternate at significantly lower rates than Groups S, UD, and UF.

\section{Method}

Apparatus. A floorless, unbaited T-maze, which has been described elsewhere (Means, Bates, \& Cahoon, 1973), was used to assess spontaneous alternation. The maze, painted gray and covered with a wire mesh top, was placed on a table that had $10-\mathrm{cm}$ squares delineated. The table was cleaned after a rat urinated or defecated and after the testing of a squad of 15 rats. White noise was used during testing to mask possible disrupting sounds.

Procedure. To both adapt the animals to the apparatus and measure exploratory activity, all rats were given a 5-min free exploration trial in the maze on 4 successive days. Spontaneous alternation testing was initiated on the day following completion of the free exploration. Each animal was given three trials a day, an initial reference trial and two alternation test trials. A trial consisted of placing a rat in the startbox, opening the door, allowing the animal to choose an arm of the maze, and closing the door behind the rat. The intertrial interval (ITI) was approximately $15 \mathrm{sec}$. If an animal failed to make a choice within 5 min, its testing was terminated for that day. The rats were tested for 10 days with all choices being recorded.

\section{Results and Discussion}

The mean number of alternations above $50 \%$ for the groups was: $S, 5.42 ; \mathrm{UD}, 5.60 ; \mathrm{UF}, 3.00 ; \mathrm{C}, 4.29$; $\mathrm{BD}, .17$; and $\mathrm{BF}, 4.90$. An analysis of variance revealed a significant difference among surgical groups on number of alternations above chance $[F(5,32)=$ $3.40, p<.05]$. A Newman-Keuls follow-up showed that Group BD alternated significantly less than did Groups C, BF, S, and UD (p < .05).

The six groups of rats were not found to differ on total maze exploratory activity. Tests of intrasession and intersession habituation revealed that all groups showed decreasing activity within the 5-min sessions and across the four sessions, but that the groups did not differ from one another. Thus, maze activity proved to be an insensitive behavioral assay, not differentiating the groups.

\section{EXPERIMENT 2 VISUAL-TACTILE DISCRIMINATION}

Impairment of visual-tactile discrimination in rats with bilateral DMT ablations has been reported 

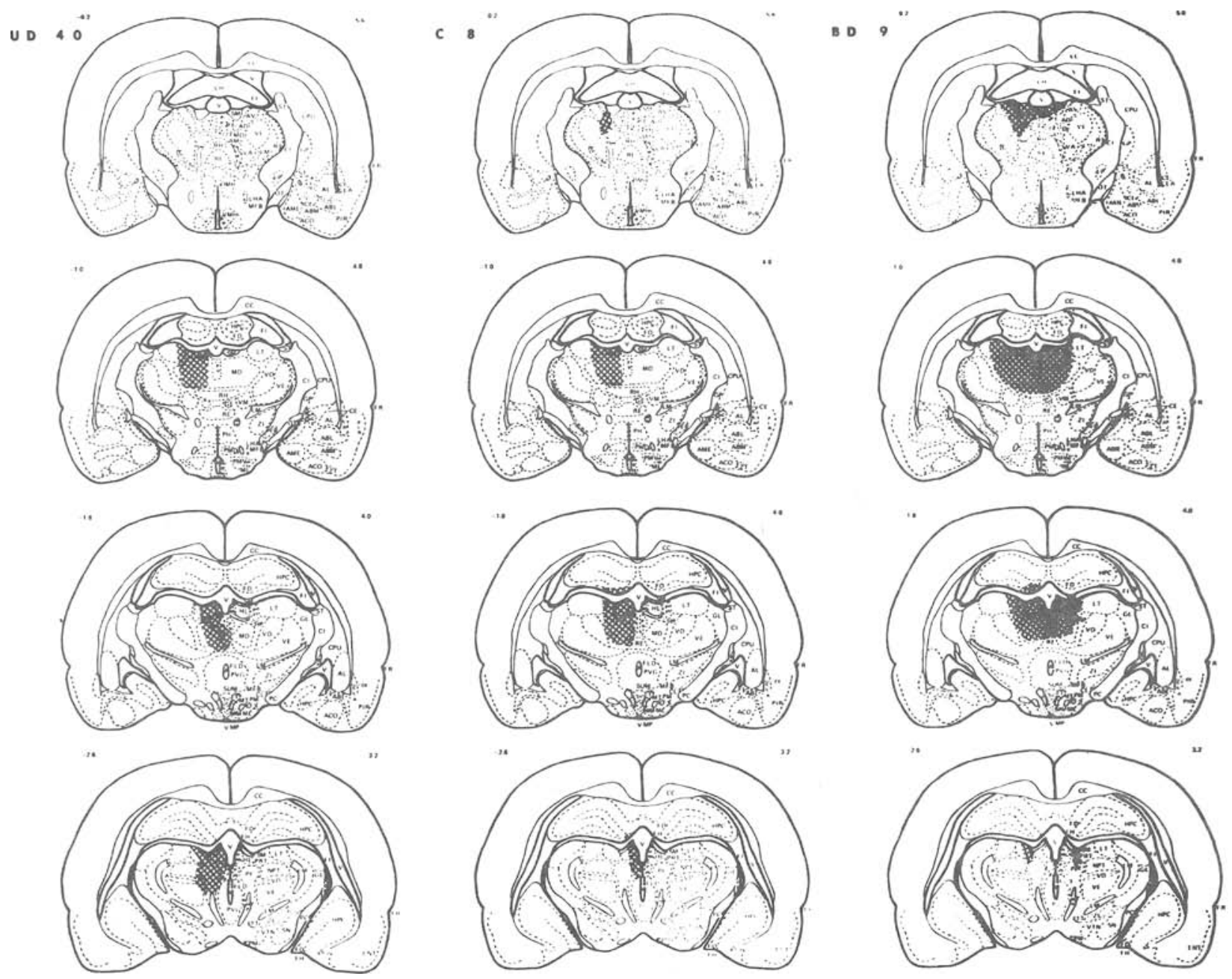

Figure 1. Reconstructions of representative medial thalamic lesions.

(Means, Huntley, Anderson, \& Harrell, 1973; Waring \& Means, 1976), while animals with unilateral DMT lesions have been found to be unimpaired (Means, Clark, \& King, 1976). To our knowledge, rats with lesions restricted to the medial frontal cortex have not been tested on a visual-tactile discrimination. Rats with frontal cortex lesions have been found to be normal on acquisition of both spatial (Bourke, 1954; Nonneman, Voigt, \& Kolb, 1974) and brightness (Hannon \& Bader, 1974; Kling \& Bartley, 1974) discrimination.

For this experiment, it was reasoned that if the medial frontal cortex and the dorsomedial thalamus form a common behavior-mediating system, then Groups $\mathrm{BD}, \mathrm{BF}$, and $\mathrm{C}$ would make significantly more errors to criterion and take significantly more sessions to reach criterion than would groups S, UD, and UF.

\section{Method}

Apparatus. A two-choice discrimination maze, described elsewhere (Means, Huntley, Anderson, \& Harrel, 1973), was used for discrimination training. The startbox, runway, choicepoint, and one goalbox were painted gray, while the other goalbox had black and white horizontal stripes. The gray goalbox had an elevated wire-mesh floor, and the black-and-white goalbox had a smooth floor. The goalboxes were movable so that the right and left positions could be interchanged.

Procedure. All rats were placed on food deprivation following their last spontaneous alternation trial. The animals were maintained at $85 \%$ of their ad-lib weight.

Maze adaptation was initiated 2 days after food deprivation had begun. The maze was baited with four $45-\mathrm{mg}$ Noyes pellets in the reinforcement cup on each goalbox. A maze adaptation trial was begun by placing a rat in the startbox and opening the door. The animal remained in the maze for $5 \mathrm{~min}$ or until all the food pellets were consumed, whichever occurred first. The maze adaptation phase lasted 5 days, with the left-right positions of the goalboxes changed each day.

Following maze adaptation, acquisition training was begun. This consisted of 10 trials per day for each animal with an ITI of approximately $5 \mathrm{~min}$. One half of the rats in each group were reinforced for entering the wire-floor, gray goalbox, and the other half were reinforced for entering the smooth-floor, striped goalbox. Reinforcement consisted of four $45-\mathrm{mg}$ Noyes pellets. If an animal did not respond after $4 \mathrm{~min}$, it was removed from the maze and an error was recorded. The subjects were tested for 15 days or until they reached criterion, whichever came first. 


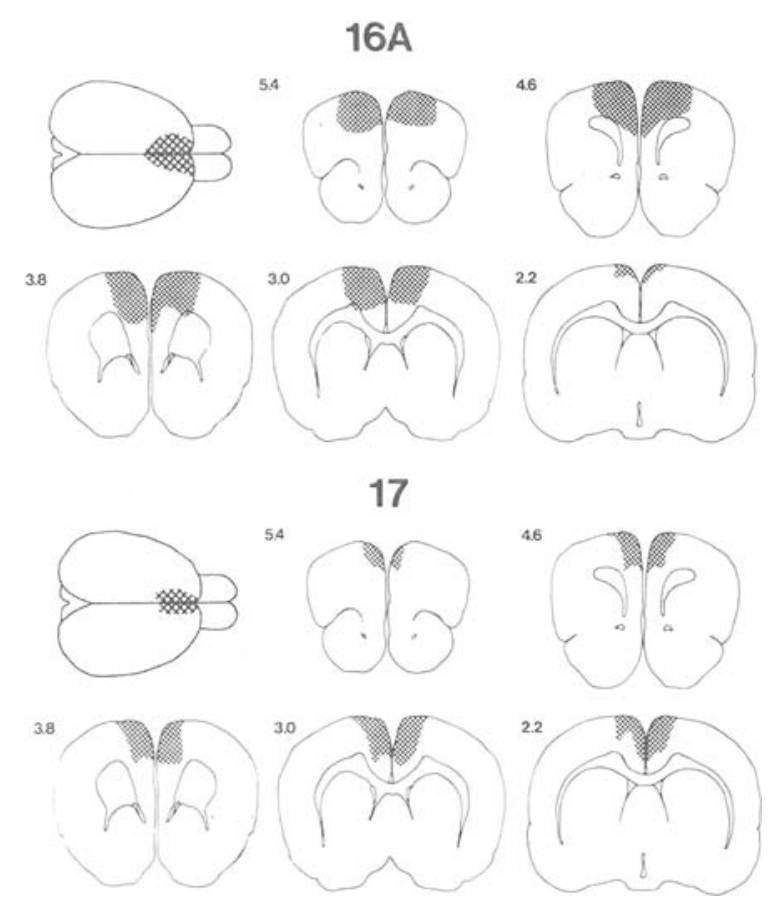

Figure 2. Lashley diagrams and frontal sections of two representative bilateral medial frontal lesions.

Every animal was tested for at least 6 days. Criterion for acquisition was 9 out of 10 correct choices for 3 consecutive days.

\section{Results and Discussion}

Table 1 contains the mean errors and mean sessions to criterion for each group. A one-way analysis of variance on errors to criterion disclosed a significant difference among the groups $[\mathrm{F}(5,32)=$ $64.48, \mathrm{p}<.001]$. A Newman-Keuls test demonstrated that Group BD made significantly more errors to criterion than any other group $(p<.01)$. There were no other significant differences among groups.

Similarly, a one-way analysis of variance for sessions to criterion showed a significant difference among groups $[F(5,32)=21.75, p<.001]$. A NewmanKeuls follow-up test revealed that Group BD took significantly more sessions to reach criterion than any other group $(\mathrm{p}<.01)$.

The results obtained on the visual-tactile discrimination task did not support the hypothesis that Groups BD, BF, and C would require a greater num-

Table 1

Mean Errors to Criterion and

Mean Sessions to Criterion

\begin{tabular}{lcc}
\hline Group & $\begin{array}{c}\text { Errors to } \\
\text { Criterion }\end{array}$ & $\begin{array}{c}\text { Sessions to } \\
\text { Criterion }\end{array}$ \\
\hline S & 10.71 & 2.57 \\
UD & 12.40 & 3.20 \\
UF & 20.33 & 3.67 \\
C & 13.86 & 3.28 \\
BD & 50.67 & 11.67 \\
BF & 14.00 & 3.20 \\
\hline
\end{tabular}

ber of trials to criterion and commit a greater number of errors to criterion. Only Group BD was deficient on the acquisition of the task. This result supports previous studies involving rats with DMT damage on the acquisition of a visual-tactile discrimination (Means et al., 1976; Waring \& Means, 1976). Previous studies on animals with prefrontal lesions have shown that impairment on discrimination tasks might depend on the particular sensory modality involved (Warren, 1964). Visual cues may have ameliorated discrimination performance deficits in prefrontally ablated animals (Glick, 1969; Gross, 1963; Pribram, Ahumada, Hartog, \& Roos, 1964; Warren, Warren, \& Akert, 1972).

\section{GENERAL DISCUSSION}

The results of spontaneous alternation and discrimination tasks reveal that the DMT and AC are not equally important for mediating these behaviors. While both anatomical (Krettek \& Price, 1977) and electrophysiological (Fuster \& Alexander, 1973) evidence reveal these structures to be highly interconnected, their respective roles in mediating behavior are clearly different. The fact that the group with bilateral AC lesions and the group with contralateral AC-DMT lesions were essentially normal on these tasks reveals that AC-MD interconnections are unnecessary to these behaviors.

It is quite likely that lesions to the AC or DMT would produce similar deficits on other tasks, such as delayed alternation. However, the deficits probably would be due to disruption of two different functions, a time-dependent and/or response-inhibition function of AC and some kind of choice function of the DMT, as rats with AC have been found to be deficient on delay (Kolb, Nonneman, \& Singh, 1974; Wikmark, Divac, \& Weiss, 1973) and reversal tasks (Bourke, 1954; Divac, 1971; Nonneman et al., 1974), while rats with DMT lesions have consistently been found to be deficient on any task involving choice (Means, Harrell, Mayo, \& Alexander, 1974; Means, Harrington, \& Miller, 1974; Means et al., 1975; Means, Hunt, Whiteside, \& Bates, 1973; Means, Huntley, Anderson, \& Harrell, 1973; Tigner, 1974; Waring \& Means, 1976; Wuensch, Broome, Harris, \& Means, 1978).

It is possible that the frontal lesions in the present experiments were incomplete or involved the wrong projection area. The MD projects to the suprarhinal frontal cortex and the orbital cortex (Krettek \& Price, 1977). The other cortical projection areas were not disturbed in the present subjects. Also, other subcortical areas, including the caudate nucleus, hippocampus, hypothalamus, and amygdala (Brutowski, 1965; Krettek \& Price, 1977; Nauta, 1964), were not destroyed.

In summary, two conclusions seem warranted 
from the present research: (1) The importance of a functional DMT for acquisition and performance of a task involving choice has been reaffirmed; and (2) the DMT and AC mediate different underlying behavioral functions.

\section{REFERENCES}

Akert, K. Comparative anatomy of frontal cortex and thalamofrontal connections. In J. M. Warren \& K. Akert (Eds.), The frontal granular cortex and behavior. New York: McGraw-Hill, 1964.

Alexander, G. E., \& Fuster, J. M. Effects of cooling prefrontal cortex on cell firing in the nucleus medialis dorsalis. Brain Research, 1973, 61, 93-105.

Bourke, W. T. The effects of frontal lobe damage upon habit reversal in the white rat. Journal of Comparative and Physiological Psychology, 1954, 47, 277-282.

Brutowski, S. Functions of prefrontal cortex in animals. Physiological Reviews, 1965, 45, 721-746.

Dember, W. N., \& Fowler, H. Spontaneous alternation behavior. Psychological Bulletin, 1958, 55, 412-428.

Divac, I. Frontal lobe system and spatial reversal in the rat. Neuropsychologia, 1971, 9, 175-183.

Divac, I., Kosmal, A., Buorklund, A., \& Lindvall. O. Subcutaneous projections to the prefrontal cortex in the rat. Abstracts of the Society for Neuroscience, 1976, 2, 134.

Divac, I., Wikmark, R. G. E., \& Gade, A. Spontaneous alternation in rats with lesions in the frontal lobes: An extension of the frontal lobe syndrome. Physiological Psychology, 1975, 3, $39-42$.

Domesick, V. B. Thalamic relationships of the medial cortex in the rat. Brain Behavior and Evolution, 1972, 6, 457-483.

Ebbesson, S. O. E., Jane, J. A., \& Schroeder, D. M. A general overview of major interspecific variations in thalamic organization. Brain, Behavior and Evolution, 1972, 6, 92-103.

Fuster, J. M. Unit activity in prefrontal cortex during delayedresponse performance: Neuronal correlates of transient memory. Journal of Neurophysiology, 1973, 36, 61-78.

Fuster, J. M., \& Alexander, G. E. Delayed response deficit by cryogenic depression of frontal cortex. Brain Research, $1970,20,85-90$.

Fuster, J. M., \& Alexander, G. E. Firing changes in cells of the nucleus medialis dorsalis associated with delayed response behavior. Brain Research, 1973, 61, 79-91.

GLICK, S. D. Discrimination learning and reversal in frontal rats as a function of cue. Physiology \& Behavior, 1969, 4, 389-392.

Gross, C. G. A comparison of the effects of partial and total lateral frontal lesions on test performance by monkeys. Journal of Comparative Physiological Psychology, 1963, 56, 41-47.

HANnon, R., \& BADER, A. A comparison of frontal pole, anterior median and caudate nucleus lesions in the rat. Physiology \& Behavior, 1974, 13, 513-521.

KLING, J. O., \& BARTLEY, K. S. Effects of frontal ablations on visual discrimination in the rat. Journal of General Psychology, 1974, 91, 305-306.

Kolb, B., Nonneman, A. J., \& Singh, R. K. Double dissociation of spatial impairments and perseveration following selective prefrontal lesions in rats. Journal of Comparative and Physiological Psychology, 1974, 87, 772-780.

Krettek, J. E., \& Price, J. L. The cortical projections of the mediodorsal nucleus and adjacent thalamic nuclei in the rat. Journal of Comparative Neurology, 1977, 171, 157-192.

LeONard, C. M. The prefrontal cortex of the rat. I. Cortical projection of the mediodorsal nucleus. II. Efferent connections. Brain Research, 1969, 12, 321-343.

LEONARD, C. M. The connections of the dorsomedial nuclei. Brain Behavior Evolution, 1972, 6, 524-541.
Means, L. W., Bates, T. W., \& Cahoon, R. U. The effects of non-reinforcement on the cue value of the odor trails of rats. Behavioral Biology, 1973, 8, 545-550.

Means, L. W.. Clark, R. J., King, G. M., \& Varing, A. E. The effects of unilateral and bilateral medial thalamic lesions on discrimination learning in the rat. Bulletin of the Psychonomic Societv, 1976, 7, 190-192.

Means, L. W., Harrell, T. H., Mayo, E. S., \& Alexander. G. B. Effects of dorsomedial thalamic lesions on spontaneous alternation, maze activity, and runway performance in the rat. Physiology \& Behavior, 1974, 12, 973-979.

Means. L. W., Harrington, J. H., \& Miller, G. T. The effect of medial thalamic lesions on acquisition of a go, no-go, tonelight discrimination task. Bulletin of the Psychonomic Society, 1974, 5, 495-497.

Means, L. W., Hershey, A. E., Waterhouse, G. J., \& Lane, C. J. Effects of dorsomedial thalamic lesions on spatial discrimination reversal in the rat. Physiology \& Behavior, 1975, 14, 725-729.

Means, L. W., Hunt, M. W., Whiteside, R. R., \& Bates, T. W. Deficient acquisition and retention of single-alternation go, no-go in rats with medial thalamic lesions. Physiological Psychology, 1973, 1, 287-291.

Means, L. W., Huntley, D. H., Anderson, H. P., \& Harrell, T. H. Deficient acquisition and retention of a visual-tactile discrimination task in rats with medial thalamic lesions. Behavioral Biology, 1973, 9, 435-450.

Means, L. W., Leander, J. D., \& Isaacson, R. L. The effects of hippocampal lesions on alternation behavior and response to stimulus change. Physiology \& Behavior, 1971, 6, 17-22.

Nauta, W. J. H. Some efferent connections of the prefrontal cortex in the monkey. In J. M. Warren \& K. Akert (Eds.), The frontal granular cortex and behavior. New York: McGrawHill, 1964.

NaUta, W. J. J. The problem of the frontal lobe: A reinterpretation. Journal of Psychiatric Research, 1971, 8, 167-187.

Nonneman, J. A., Voight, J., \& Kolb, B. E. Comparisons of behavioral effects of hippocampal and prefrontal cortex lesions in the rat. Journal of Comparative and Physiological Psychology, 1974, 87, 249-260.

Pribram, K., Ahumada, A., Hartog, J., \& Roos, L. A progress report on the neurobiological processes disturbed by frontal lesions in primates. In J. M. Warren \& K. Akert (Eds.), The frontal granular cortex and behavior. New York: McGraw-Hill, 1964.

Tigner, J. C. The effects of DMT lesions and learning reversal, and alternation behavior in the rat. Physiology \& Behavior, 1974, 12, 13-17.

Waring, A. E., \& Means, L. W. The effect of medial thalamic lesions on emotionality, activity, and discrimination learning in the rat. Physiology \& Behavior, 1976, 17, 181-186.

WARREN, J. M. The behavior of carnivores and primates with lesions in the prefrontal cortex. In J. M. Warren \& K. Akert (Eus.), The frontal granular cortex and behavior. New York: McGraw-Hill, 1964.

Warren, J. M., Warren, H. B., \& Akert, K. The behavior of chronic cats with lesions in the frontal association cortex. Acta Neurobiologica Experimentalis, 1972, 32, 361-392.

WiкмaRK, R. G. E., Divac, I., \& Weiss, R. Retention of spatial delayed alternation in rats with lesions in the frontal lobes. Brain, Behavior and Evolution, 1973, 8, 329-339.

Wuensch, K. L., Broome, B., Harris, E. C., \& Means, L. W. Effects of dorsomedial thalamic lesions and amphetamine on acquisition and retention of a visual pattern discrimination escape task. Physiological Psychology, 1978, 6, 288-293.

(Received for publication June 4, 1979; revision accepted April 11, 1980.) 